\title{
Health Plan Budget Impact Analysis for Pimecrolimus
}

\author{
JANE CHANG, MPH, and JENNIFER SUNG, PharmD, MS
}

\begin{abstract}
OBJECTIVE: Budget impact models are useful tools for managed care organizations to make drug formulary decisions. The objective of this study was to estimate the incremental budgetary change in per-member-per-month (PMPM) medical and pharmacy costs for atopic dermatitis (AD) or eczema after the introduction of pimecrolimus cream $1 \%$, a topical calcineurin inhibitor.

METHODS: Estimates of the percentage of patients seeking care, treatment patterns, and quantities of medications dispensed for $A D$ were measured using 2001 and 2002 medical and pharmacy records in a proprietary database for health plans distributed throughout the United States. Approximately 2.5 million health plan members had continuous health insurance coverage during the study period. Costs for medications were assigned using the 2003 wholesale acquisition cost, and costs for physician visits were based on average 2003 Medicare reimbursement rates. Efficacy data from clinical trials were used to model the impact of pimecrolimus on subsequent physician visits. Sensitivity analyses were performed to evaluate the impact of varying the percentage of patients seeking care, practice patterns, medication quantities, percentage of pimecrolimus users, and levels of patient cost sharing.
\end{abstract}

RESULTS: The estimated percentage of health plan members seeking care for $A D$ in 2001 was $3.2 \%$. The estimated total cost PMPM for AD treatment prior to introduction of pimecrolimus was $\$ 0.362$ for all covered lives, assuming no patient cost sharing. In the year after its introduction, $5.2 \%$ of the $A D$ population filled a prescription for pimecrolimus. The incremental increase in pharmacy benefit cost was $\$ 0.008$ PMPM in 2003 dollars, but the total incremental medical and pharmacy cost was $\$ 0.002$ PMPM after accounting for the projected reduction in physician visit costs, representing a $0.7 \%$ increase in all $A D$-related costs. Based on sensitivity analyses, the incremental total cost PMPM after the introduction of pimecrolimus ranged from $-\$ 0.004$ to $\$ 0.026$.

CONCLUSION: Using claims data for the medical treatment of AD in 2001-2002 and the utilization of pimecrolimus, the addition of pimecrolimus as a treatment option for AD had a minimal impact on PMPM costs for AD-related care in 2003 dollars. As with all pharmacoeconomic models, health plans should perform their own budget forecasting using assumptions derived from their own pharmacy and medical claims data.

KEYWORDS: Atopic dermatitis, Budget impact model, Elidel, Pimecrolimus, Treatment costs, Practice patterns

J Manag Care Pharm. 2005:11(1):66-73

\section{Authors}

JANE CHANG, MPH, is a health economics and outcomes research fellow, Duke Clinical Research Institute, Durham, North Carolina, and Novartis Pharmaceuticals Corporation, East Hanover, New Jersey; JENNIFER SUNG, PharmD, MS, is director, outcomes research, Department of Health Economics and Outcomes Research, Novartis Pharmaceuticals Corporation, East Hanover, New Jersey.

AUTHOR CORRESPONDENCE AND REQUEST FOR REPRINTS: Jane Chang, MPH, Health Economics and Outcomes Research Fellow, Health Economics and Outcomes Research, Novartis Pharmaceuticals Corporation, One Health Plaza, East Hanover, NJ 07936-1080. Tel: (862) 778-5338; Fax: (973) 781-2439;

E-mail: jane.chang@pharma.novartis.com

Copyright $\odot$ 2005, Academy of Managed Care Pharmacy. All rights reserved.
Editor's Note: This article, highlighting a budget impact analysis, is published coincident with an overview of atopic dermatitis that focuses on nonsteroidal topical therapies, particularly pimecromlimus. Budget impact forecasting is a component of pharmacoeconomic analyses recommended in the AMCP Format (dossier) process.

A topic dermatitis (AD) is a chronic disease of the skin characterized by itching, redness, and swelling. Primarily affecting infants and children, it is estimated that $20 \%$ of infants and young children are affected by AD, while $60 \%$ of these children continue to experience symptoms into adulthood. ${ }^{1}$ Overall, a 2 - to 3 -fold increase in AD has been observed over the past 30 years, and it is currently believed to affect $10 \%$ to $15 \%$ of the population at some point in childhood. ${ }^{2,3}$ The prevalence of AD has risen along with asthma and other atopic diseases. This epidemiological change is attributed to environmental factors (such as allergens and pollutions) and lifestyle factors (such as diet and stress). ${ }^{4}$

Fifteen percent to $30 \%$ of AD patients are estimated to have coexistent asthma, and nearly $80 \%$ of children with $\mathrm{AD}$ will subsequently develop allergic airway disease, such as asthma or allergic rhinitis. ${ }^{5}$ As such, AD has been suggested as an "entry point" for subsequent allergic disease. ${ }^{6}$ Researchers have hypothesized that $\mathrm{AD}$ and asthma share common pathophysiologic mechanisms related to early immunoglobulin (Ig) E production and consequent allergen/IgE reactivity ${ }^{7-10} ; 3$ of the $\mathrm{AD}$ linkages have been found to correspond with known asthma loci, indicating that $\mathrm{AD}$ shares genetic determinants with asthma. ${ }^{6}$

In 1997, the direct medical cost of AD in the United States for patients aged $<65$ years was estimated to range from $\$ 1$ billion to $\$ 4$ billion depending on the extent to which costs for comorbid conditions were considered. ${ }^{11}$ However, these estimates do not include costs for items or services not paid by third-party payers such as patient copayments for office visits and prescription medications as well as for over-the-counter (OTC) products. A study conducted in a large managed care organization calculated that the total burden of $\mathrm{AD}$, including direct medical costs, out-of-pocket expenses, and lost productivity, amounted to an annual cost of $\$ 609$ per patient, with $27 \%$ attributed to direct medical costs. ${ }^{12}$ Outpatient visits and prescription medications accounted for $63 \%$ and $30 \%$ of the direct medical costs, respectively. Productivity loss accounted for almost $50 \%$ of the total burden, and the impact was significantly higher for individuals with severe disease.

Traditionally, treatment has primarily involved the use of emollients to ameliorate dry skin and short-term use of topical 
corticosteroids to treat acute disease flares. Although treatment with topical corticosteroids is efficacious, long-term use of these agents can cause skin atrophy and suppression of the hypothalamic-pituitary-adrenal (HPA) axis. ${ }^{13-16}$ These adverse events have led patients and practitioners to express the need for alternative therapeutic options for the treatment of $\mathrm{AD} \cdot{ }^{17,18}$ The introduction of pimecrolimus (Elidel) cream 1\% in January 2002 provided practitioners with a nonsteroidal, topical treatment option that has been shown to be effective in AD management. ${ }^{19-22}$ In addition, early use of pimecrolimus has been shown to reduce or eliminate the need for topical corticosteroids. ${ }^{21}$

A budget impact model was developed to estimate the annual direct medical cost of treatment for $\mathrm{AD}$ and to estimate the incremental budgetary impact of the introduction of pimecrolimus as a treatment option for $\mathrm{AD}$ or eczema.

\section{Methods}

A retrospective pre-post study design was implemented to estimate treatment cost of $\mathrm{AD}$ prior to and after the market introduction of pimecrolimus in January 2002. The calculation was replicated in a Microsoft Excel-based spreadsheet model, which serves as a flexible analytic tool to examine the budgetary impact of the introduction of pimecrolimus from both a societal and a managed care organization perspective. The analysis included AD costs from outpatient physician visits and medications. Hospital costs were not included because inpatient care for this condition is extremely rare..$^{12}$

Claims data from MarketScan (MedStat, Ann Arbor, Michigan) served as the primary data source for estimates of resource utilization. This database provided integrated pharmacy and medical claims from various health plans in the United States. The analysis cohort consisted of individuals who were continuously enrolled in a health plan in 2001 and 2002 and who had a claim for at least one office visit with a diagnosis code indicating atopic dermatitis or eczema (ICD-9-CM: 691.8, "other atopic dermatitis"; ICD-9-CM: 692.9, "dermatitis not otherwise specified") in either year. Based on the structure of the claims database, 5 diagnosis-related code fields were reviewed for these AD diagnoses. Most office visits (92.8\%) captured in the model were identified based on the primary diagnosis code, however. In this paper, all references to $\mathrm{AD}$ are inclusive of eczema.

Annual rates of physician visits for AD were estimated separately for generalist and specialist physicians. ${ }^{23}$ Generalist physicians consisted of internists, family practitioners, and pediatricians. Specialist physicians represented practitioners of various therapeutic areas, primarily dermatology.

To estimate annual costs for medications, the model was designed to multiply the proportion of patients with $\mathrm{AD}$ who were treated with different types of medications for $\mathrm{AD}$ by the average number of each type of medication used each year. Medications were categorized as brand prescription corticosteroids, generic prescription corticosteroids, OTC
TABLE 1) Unit Costs Applied in Base-Case Analysis

\begin{tabular}{l|c|c}
\hline Resource & Cost (2003 \$) & \multicolumn{1}{c}{ Source $^{23,24}$} \\
\hline $\begin{array}{l}\text { Office Visits } \\
\text { Generalists }\end{array}$ & 51.15 & $\begin{array}{c}\text { 2003 Medicare National Physician } \\
\text { Fee Schedule: CPT 99213 } \\
\text { 2003 Medicare National Physician } \\
\text { Fee Schedule: CPT 99243 }\end{array}$ \\
\hline $\begin{array}{l}\text { Medications } \\
\text { Brand corticosteroid* } \\
\text { Generic corticosteroid } \dagger\end{array}$ & 28.29 & WAC, www.analysource.com \\
OTC corticosteroid $\ddagger$ & 116.49 & WAC, www.analysource.com \\
Tacrolimus\& & 1.80 & WAC, www.analysource.com \\
Pimecrolimus\| & 47.96 & WAC, www.analysource.com \\
\hline
\end{tabular}

* Cutivate (fluticasone propionate) cream 0.05\%, 30 grams.

† Triamcinonolone acetonide cream 0.1\%, 30 grams.

\#ydrocortisone cream 1\%, 30 grams.

$\S$ Tacrolimus ointment $0.03 \%$, 30 grams

II Pimecrolimus cream 1\%, 30 grams.

WAC $=$ wholesale acquisition cost; OTC = over the counter.

corticosteroids, tacrolimus (Protopic), or pimecrolimus. The wholesale acquisition cost (WAC) was used to estimate medication costs based on 30 gram tubes for all medications considered (the WAC cost for 30 gram tube pimecrolimus $1 \%$ was effective on January 7 , 2003). ${ }^{24}$ Because OTC treatments are not captured in the MarketScan data, published data were used to estimate the utilization of OTC topical corticosteroids for $\mathrm{AD} .{ }^{25}$ The proportions of patients taking each type of prescription medication were based on utilization patterns in the MarketScan data. To simplify the model, when patients had claims for more than one type of medication (6.4\% of patients), treatment classification was based on the most frequently prescribed medication. However, after the introduction of pimecrolimus, "cotreatment" with pimecrolimus and corticosteroids was accounted for in the model. Unit costs assigned to physician visits and medications are reported in Table 1.

Migration to treatment with pimecrolimus was based on the proportions of patients switching from previous treatments (or no treatment) to pimecrolimus. The annual number of tubes of topical medications dispensed to each patient was also computed and integrated into the model.

Data from a double-blind, multicenter, randomized, parallel-group clinical trial of 713 children with AD, ranging from age 2 to 17 years, were used to model the impact of pimecrolimus on the number of physician visits and use of corticosteroids. ${ }^{20}$ In the trial, 476 and 237 pediatric AD patients were randomized to the pimecrolimus treatment and standard treatment, respectively. Patients randomized to standard treatment received emollients as the maintenance treatment and topical corticosteroids for the flare management. Based on the trial data, the budget impact model assumed that $57.4 \%$ of patients treated with pimecrolimus would not require cotreatment with corticosteroids. The model also used the $31.4 \%$ reduction in the 


\begin{tabular}{|c|c|c|c|}
\hline $\begin{array}{l}\text { Anr } \\
\text { Plar } \\
\text { Afte } \\
\text { Bas }\end{array}$ & \multicolumn{3}{|c|}{$\begin{array}{l}\text { Annual Costs for a Hypothetical Health } \\
\text { Plan of } 1 \text { Million Members Prior to and } \\
\text { After the Introduction of Pimecrolimus: } \\
\text { Base-Case Results }\end{array}$} \\
\hline & $\begin{array}{l}\text { Prior to } \\
\text { Introduction } \\
\text { of } \\
\text { Pimecrolimus } \\
\text { Total (\$) } \\
\text { [PMPM] }\end{array}$ & $\begin{array}{l}\text { After } \\
\text { Introduction } \\
\text { of } \\
\text { Pimecrolimus } \\
\text { Total (\$) } \\
\text { [PMPM] }\end{array}$ & $\begin{array}{l}\text { Incremental } \\
\text { Costs }(\$) \\
\text { Total } \\
\text { (\% Change) } \\
\text { [PMPM] }\end{array}$ \\
\hline $\begin{array}{l}\text { Medications } \\
\text { Brand corticosteroids } \\
\text { Generic corticosteroids } \\
\text { OTC corticosteroids } \\
\text { Tacrolimus } \\
\text { Pimecrolimus } \\
\text { jubtotal }\end{array}$ & $\begin{array}{r}194,282 \\
26,527 \\
39,297 \\
44,690 \\
0 \\
304,796 \\
{[\$ 0.025]}\end{array}$ & $\begin{array}{r}191,088 \\
26,062 \\
38,424 \\
35,686 \\
109,596 \\
400,856 \\
{[\$ 0.033]}\end{array}$ & $\begin{array}{r}-3,194(-1.6) \\
-465(-1.8) \\
-873(-2.2) \\
-9,004(-20.1) \\
109,596 \\
96,060(-31.5) \\
{[\$ 0.008]}\end{array}$ \\
\hline $\begin{array}{l}\text { Gysician visits } \\
\text { Generalists } \\
\text { Specialists } \\
\text { ubtotal }\end{array}$ & $\begin{array}{r}1,918,330 \\
2,121,050 \\
4,039,380 \\
{[\$ 0.337]}\end{array}$ & $\begin{array}{r}1,886,738 \\
2,086,119 \\
3,972,857 \\
{[0.331]}\end{array}$ & $\begin{array}{r}-31,592(-1.6) \\
-34,931(-1.6) \\
-66,523(-1.6) \\
{[\$-0.006]}\end{array}$ \\
\hline otal costs & $\begin{array}{r}4,344,176 \\
{[\$ 0.362]}\end{array}$ & $\begin{array}{r}4,373,713 \\
{[\$ 0.364]}\end{array}$ & $\begin{array}{r}29,537(0.7) \\
{[\$ 0.002]}\end{array}$ \\
\hline
\end{tabular}

PMPM= per member per month; OTC $=$ over the counter

number of flares observed among patients using pimecrolimus in the trial as a proxy for a reduction in physician visits, assuming that fewer flares led to fewer physician visits.

\section{Benefit Design}

The budget impact model was designed to incorporate patient cost sharing. For prescription medications, 1-, 2-, or 3-tier copayment or coinsurance designs could be applied. Also, copayments for office visits to generalists and specialists could be applied separately. However, unless specified, patient cost sharing was not considered as all patient copayments (or coinsurance rates) were set to $\$ 0$ (or $0 \%$ ).

\section{Cost Metrics}

The resulting estimates were reported in 2003 U.S. dollars in 2 ways: (1) aggregate costs based on 1 million hypothetical enrollees and (2) cost per member per month (PMPM).

\section{Sensitivity Analysis}

One-way sensitivity analyses were carried out to evaluate the impact of varying model parameters without patient cost sharing. Key parameters included were the cost of medications, percentage of patients seeking care for $\mathrm{AD}$, treatment patterns, and treatment efficacy. Sensitivity analyses of prescription medication costs considered a relative change of $\pm 50 \%$ in WAC and an alternative pricing scenario based on average wholesale pricing (AWP) ${ }^{24}$ Other sensitivity analyses evaluated estimates of the percentage of patients seeking care, percentage of pimecrolimus users, average number of pimecrolimus prescriptions, and the impact of pimecrolimus on corticosteroid use and subsequent physician visits for AD by a relative change of $\pm 50 \%$.

To evaluate a worst-case (highest annual cost and incremental cost) scenario, the following estimates were jointly increased or decreased by $50 \%$ relative to the estimates used in the base-case analysis:

\section{Worst-case Scenario}

- Cost of pimecrolimus (+50\%)

- Percentage of pimecrolimus users $(+50 \%)$

- Average number of pimecrolimus prescriptions (+50\%)

- Reduction in the proportion of pimecrolimus-treated patients requiring cotreatment with prescription corticosteroids (-50\%)

- Reduction in the number of AD-related physician visits for patients treated with pimecrolimus (-50\%)

To evaluate a best-case (lowest annual cost and incremental cost) scenario, the following estimates were jointly increased or decreased by $50 \%$ from the estimates used in the base-case analysis:

\section{Best-case Scenario}

- Cost of pimecrolimus (-50\%)

- Percentage of pimecrolimus users (-50\%)

- Average number of pimecrolimus prescriptions (-50\%)

- Reduction in the proportion of pimecrolimus-treated patients requiring cotreatment with prescription corticosteroids $(+50 \%)$

- Reduction in the number of AD-related physician visits for patients treated with pimecrolimus ( $+50 \%)$

From the payers' perspective, the budgetary impact of imposed patient cost sharing was evaluated in the model by incorporating patient copayments for office visits and medications into the base case. Office visits to generalists required a $\$ 10$ copayment while visits to specialists assumed a $\$ 20$ copayment. For medications, brand-name corticosteroids, tacrolimus, and pimecrolimus were assumed to have a $\$ 20$ copayment while generic corticosteroids had a $\$ 10$ copayment or were equal to the cost of the medication, whichever was less. OTC corticosteroids were also assumed to be paid entirely by the patient. Lastly, the 2003 pimecrolimus utilization data derived from MarketScan were also utilized along with 2004 pricing data for physician visit ${ }^{23}$ and drug costs, ${ }^{24}$ assuming no patient cost sharing.

\section{Results}

\section{Base-Case Analysis}

Approximately 2.5 million individuals who had continuous health insurance coverage throughout 2001 and 2002 were included. Among these individuals, a total of 80,119 patients (3.2\%) had a diagnosis of AD (or eczema) in 2001. An assessment of their resource utilization indicated that these 
Percentage of Patients Seeking Care for AD $\pm 50 \%$

Percentage of Pimecrolimus Users $\pm 50 \%$

Average Number of Pimecrolimus Prescription $\pm 50 \%$

Reduction of Patient Requiring Steroid $\pm 50 \%$

Reduction of Physician Visits $\pm 50 \%$

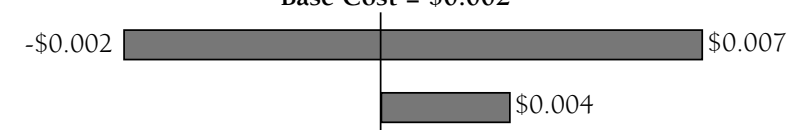

$\$ 0.004$

$\$ 0.004$

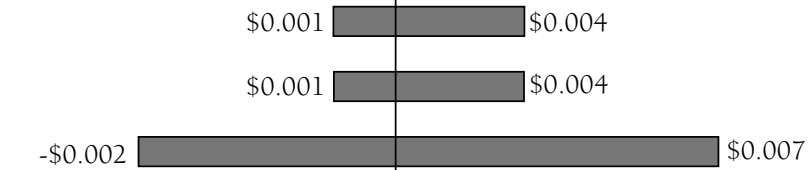

$-\$ 0.002$

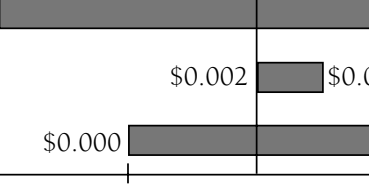

$\$ 0.003$

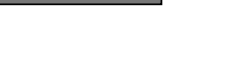

0.000

0.005

$\$ 0.005$

Incremental Total Cost PMPM (\$)

* Costs are presented in 2003 U.S. dollars.

$P M P M=$ per member per month; $W A C=$ wholesale acquisition cost; $A D=$ atopic dermatitis .

patients made an average of 1.17 visits per year to generalist physicians and 0.57 visits per year to specialists for the treatment of AD. Among the AD patients identified in the 2001 dataset, $13.7 \%$ received brand corticosteroids, $17.9 \%$ received generic corticosteroids, and $1.4 \%$ received tacrolimus. On average in 2001, patients filled a total of 1.6 prescriptions for brand corticosteroids, 1.6 prescriptions for generic corticosteroids, and 2.2 prescriptions for tacrolimus. The model results showed that physician visit costs comprised $93.0 \%$ of the total cost in the management of $\mathrm{AD}$ before the introduction of pimecrolimus. Based on a hypothetical health care plan with 1 million enrollees with no patient cost sharing, annual medication costs for AD were estimated at $\$ 304,796$, and annual physician visit costs were estimated at $\$ 4,039,380$ (Table 2 ). When combining costs for medications and physician visits, the total cost PMPM was approximately $\$ 0.362$.

After the introduction of pimecrolimus, $4.6 \%$ of patients previously prescribed brand corticosteroids, $4.7 \%$ of patients previously prescribed generic corticosteroids, and 5.2\% of patients using OTC corticosteroids or no corticosteroids (including patients with their first diagnosis of $A D$ in 2002) migrated to treatment with pimecrolimus. In addition, $20.2 \%$ of patients who were previously prescribed tacrolimus in 2001 switched to treatment with pimecrolimus in 2002. Overall, it was estimated that $5.2 \%$ of patients with $\mathrm{AD}$ received a prescription for pimecrolimus, and these patients filled an average of 1.5 prescriptions in 2002. Assuming no patient cost sharing, aggregate medication costs for $\mathrm{AD}$ increased by $31.5 \%$ to $\$ 400,856$, and total physician visit costs decreased by $1.6 \%$ to $\$ 3,972,857$ after introduction of pimecrolimus. Using the cost PMPM metric, total costs increased by $\$ 0.002$ to $\$ 0.364$ PMPM, representing a $0.7 \%$ increase.

\section{Sensitivity Analysis}

Figure 1 summarizes the findings from 1-way sensitivity analyses assuming no patient cost sharing. The 3 primary cost drivers in the model were the cost of pimecrolimus, the annual number of pimecrolimus prescriptions, and the reduction in physician visits for patients using pimecrolimus. Since these cost drivers affect only the $\mathrm{AD}$ treatment costs after pimecrolimus introduction, treatment costs prior to the introduction in these 3 analyses and the base case are the same. When either the cost of pimecrolimus or the annual number of tubes of the medication dispensed was decreased by $50 \%$, medication costs only increased by $13.5 \%$ and total cost decreased by $0.6 \%$ (or by $\$ 0.002$ PMPM) after the introduction of pimecrolimus to the marketplace as compared with the previous year without pimecrolimus. When increasing the cost of pimecrolimus or the number of tubes of pimecrolimus dispensed by $50 \%$, medication costs increased by $49.5 \%$ and total cost increased by $1.9 \%$ (or by $\$ 0.007 \mathrm{PMPM}$ ). When the reduction in physician visits due to pimecrolimus was increased by 50\% from $31.4 \%$ to $47.10 \%$, physician visit costs decreased by $2.5 \%$ and total costs decreased by $0.1 \%$ (or by $<\$ 0.001$ PMPM). When the reduction in physician visits resulting from pimecrolimus was reduced to $15.7 \%$, physician visit costs decreased by $0.8 \%$ and total costs increased by $1.5 \%$ (or by $\$ 0.005$ PMPM). Across the 3 sets of sensitivity analyses, total cost PMPM after the introduction of pimecrolimus ranged from $\$ 0.360$ to $\$ 0.369$, representing differences of approximately $\pm \$ 0.005$ PMPM relative to the base case of $\$ 0.364$ PMPM.

When the AWP was substituted for the WAC for all medications, medication costs increased to $\$ 399,338$ for the year prior to the introduction of pimecrolimus and $\$ 519,028$ in the year after its introduction to the marketplace, representing 
FIGURE 2 Sensitivity Analysis: Impact of the Percentage of Patients Seeking Care for AD on PMPM Costs After the Introduction of Pimecrolimus*

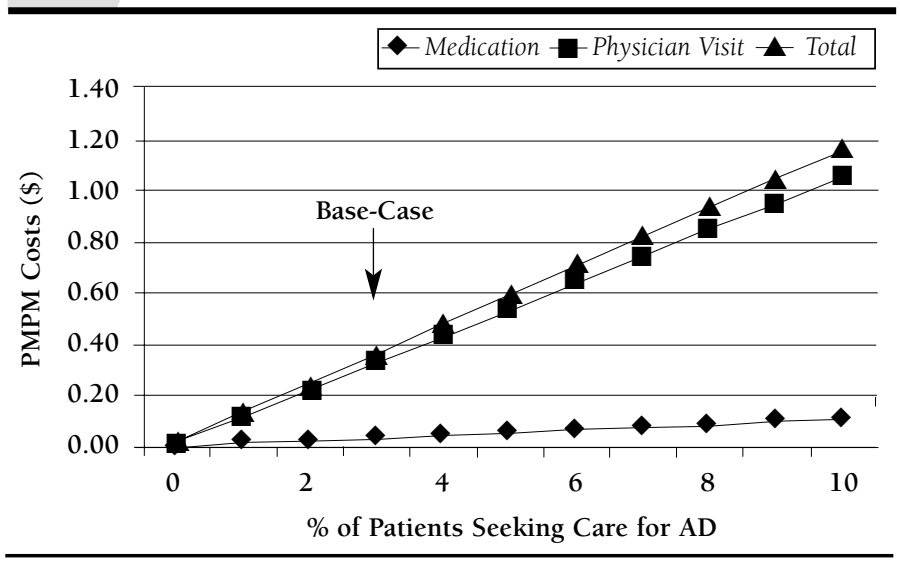

* Costs are presented in 2003 U.S. dollars.

$A D=$ atopic dermatitis; $P M P M=$ per member per month

FIGURE 3 Sensitivity Analysis: Impact on PMPM Costs of Migration to Pimecrolimus*

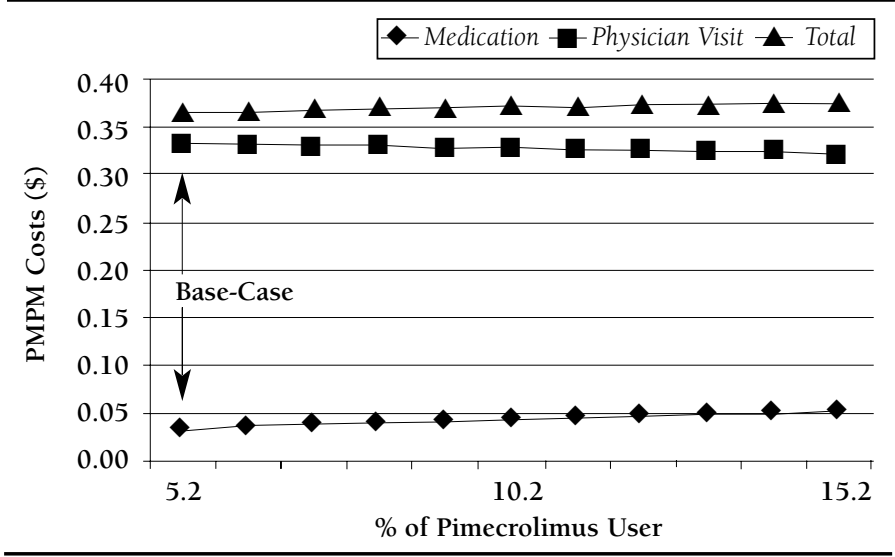

* Costs are presented in 2003 U.S. dollars.

PMPM = per member per month.

an increase of $30.0 \%$ in medication costs; total cost PMPM increased by $1.2 \%$ (or by $\$ 0.004$ PMPM).

Varying the percentage of patients seeking care for $\mathrm{AD}$ did not affect the percentage change in costs after the introduction of pimecrolimus but had a significant impact on the magnitude of the cost estimates. For each 1\% absolute increase, medication costs after the introduction of pimecrolimus increased by $\$ 125,267$ (\$0.010 PMPM); total costs also increased by $\$ 1,366,785$ ( $\$ 0.114$ PMPM) per percentage point (Figure 2).
In the sensitivity analysis where the percentage of pimecrolimus users was increased, for each $1 \%$ absolute increase, medication costs increased by approximately $\$ 22,322$ ( $\$ 0.002$ PMPM), and total costs increased by approximately $\$ 9,669$ ( $\$ 0.001$ PMPM) after the introduction of pimecrolimus (Figure 3). The relative change of $\pm 50 \%$ in the reduction on corticosteroid use among pimecrolimus users only had a minimal impact of approximately $\pm \$ 0.001$ PMPM relative to the base case.

Figure 4 summarizes the worst- and best-case scenarios. Variations in model parameters affected only the AD treatment costs after the introduction of pimecrolimus so treatment costs prior to pimecrolimus introduction in these scenarios and in the base-case scenario are the same. In the worst-case scenario, using estimates and assumptions resulting in the highest costs to the health care system including no patient cost sharing, medication costs increased by $117.3 \%$ to $\$ 662,217$, physician visit costs decreased by $1.2 \%$ to $\$ 3,989,488$, and the total cost increased by $7.1 \%$ to $\$ 4,651,704$ after the introduction of pimecrolimus. Using the PMPM measure, medication costs increased from $\$ 0.025$ to $\$ 0.055$, physician visit costs decreased from $\$ 0.337$ to $\$ 0.333$, and total costs increased from $\$ 0.362$ to $\$ 0.388$.

In the best-case scenario, using estimates and assumptions resulting in the lowest costs and assuming no patient cost sharing, medication costs increased by $1.4 \%$ to $\$ 309,115$, physician visit costs decreased by $1.2 \%$ to $\$ 3,989,488$, and the total cost decreased by $1.0 \%$ to $\$ 4,298,602$ after the introduction of pimecrolimus. Using the PMPM metric, medication costs increased by $<\$ 0.001$, physician visit costs decreased from $\$ 0.337$ to $\$ 0.333$, and total costs decreased from $\$ 0.362$ to $\$ 0.358$. The impact of decreasing the percentage of pimecrolimus users and increasing the impact of pimecrolimus on subsequent physician visits in the best-case scenario had the same impact as increasing the percentage of pimecrolimus users and decreasing the impact on subsequent physician visits in the worst-case scenario. Thus, the impact on costs for outpatient physician visits was the same in both scenarios.

From the perspectives of payers and patients, the impact of imposing patient cost sharing was considerable. Prior to the introduction of pimecrolimus, for a hypothetical population of 1 million enrollees, total annual costs to the payer were estimated at $\$ 3,383,165$ (\$0.282 PMPM) and total annual costs for patients were estimated at $\$ 961,011$ (\$0.080 PMPM). After its introduction, total annual costs to the payer actually decreased slightly to $\$ 3,379,504$ (\$0.282 PMPM) and increased to $\$ 994,209$ ( $\$ 0.082$ PMPM) for the patients. Thus, after imposing patient cost sharing, the managed care organizations accrued a $0.1 \%$ savings in total costs in the year following the introduction of pimecrolimus while total cost for patients increased by $3.5 \%$.

An analysis update using 2003 MarketScan data indicated that the estimated percentage of $\mathrm{AD}$ patients seeking care was 
2.9\%. Among these AD patients, $8.4 \%$ were prescribed pimecrolimus and used approximately 75 grams per year. If a health plan were to place pimecrolimus on their formulary with 2004 pricing and without patient cost sharing, medication costs would be $\$ 572,122$ (\$0.048 PMPM) and physician costs would be $\$ 3,718,082$ (\$0.310 PMPM), resulting in a total cost PMPM of $\$ 0.358$, an increment of $\$ 0.015$ from before formulary placement.

\section{Discussion}

$\mathrm{AD}$ is a prevalent disease and imposes great financial burden on the health care system and even more so on individuals when considering out-of-pocket medical expenses and indirect costs due to loss of productivity. ${ }^{12}$ The evidence of $\mathrm{AD}$ being a risk factor for childhood asthma is convincing., ${ }^{5,-10,26}$ Although it remains to be proven that the appropriate management of $\mathrm{AD}$ is effective in preventing other allergic diseases, future disease prevention is an important focus in developing treatment guidelines in light of the medical and economic impact of the increasing prevalence of allergic diseases. Budget impact models provide a valuable tool to health plans in making formulary decisions. Such models allow managers to gauge the potential economic impact resulting from the introduction of a new pharmacological treatment on medical and pharmacy budgets. This budget impact model quantifies both the pharmacy and medical costs for patients with AD using actual treatment patterns as measured in a claims database.

Given pimecrolimus usage in the insured marketplace after its introduction, it appears that overall health care budgets for AD-related care will be modestly affected-by approximately $0.7 \%$. Our analysis also showed that medication costs for AD prior to pimecrolimus introduction are relatively low at approximately \$0.025 PMPM, even in consideration of patients' out-of-pocket expenses for prescription copayments and OTC medications. The introduction of pimecrolimus was estimated to increase medication costs by about $\$ 0.008$ PMPM, or approximately $\$ 96,000$ annually for a health plan with 1 million beneficiaries. This increase in medication costs was offset by a reduction in estimated costs for outpatient physician visits of approximately $\$ 66,500$, or $\$ 0.006$ PMPM. The net increase in total cost was estimated at approximately $\$ 29,500$, or $\$ 0.002$ PMPM.

Sensitivity analysis was conducted to provide a range of estimates a health plan might expect to see when varying assumptions regarding treatment patterns. In a hypothetical cohort of 1 million health plan members, total costs after the introduction of pimecrolimus to the marketplace ranged from $\$ 4,298,602$ to $\$ 4,651,704$. The total cost PMPM ranged from $\$ 0.358$ to $\$ 0.388$, representing an incremental PMPM from $-\$ 0.004$ to $\$ 0.026$. Given that most health plans provide medication benefits at $\$ 25$ to $\$ 35$ PMPM, the relative impact of the addition of pimecrolimus in the first year after its introduction was relatively minimal, even in the worst-case scenario.

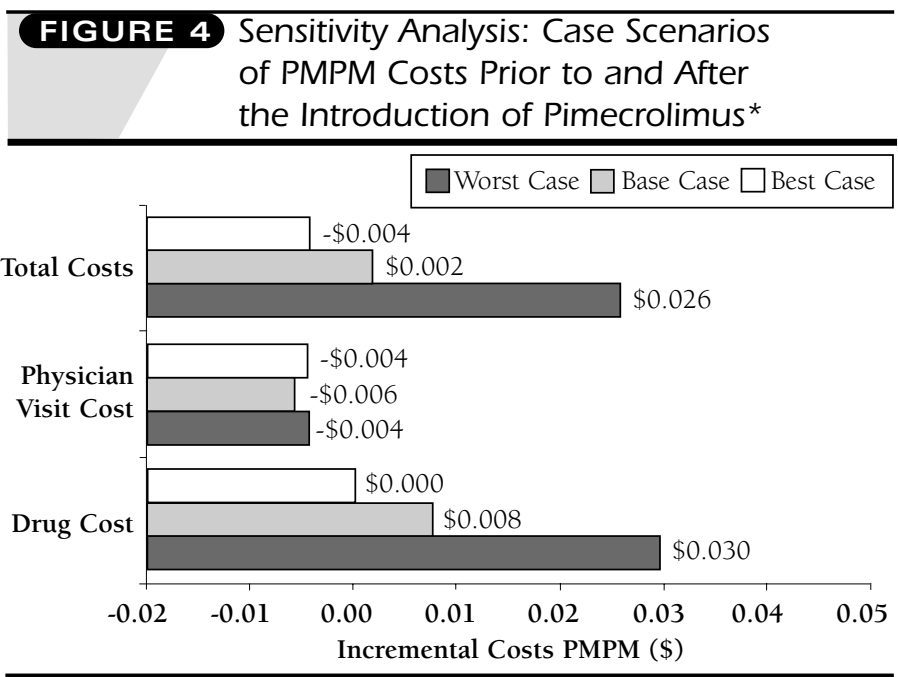

* Costs are presented in 2003 U.S. dollars.

PMPM= per member per month.

\section{Limitations}

One limitation of this study is that the proportion of patients switching from other therapies to pimecrolimus was based on data from the first year after the market introduction of pimecrolimus. This proportion may or may not pertain to subsequent years, and the use of pimecrolimus would be expected to increase over time. Health plans should perform their own budget forecast modeling using assumptions derived from their own pharmacy and medical claims data.

Our findings may not be generalizable to plans with other cost-sharing arrangements; for example, migration rates to pimecrolimus in a given health plan may differ from the data found in this proprietary database due to different formulary structures and copayment requirements. Nevertheless, this model is intended to assist managed care organizations to estimate potential budgetary impact upon the addition of pimecrolimus to the formulary. Even though our base-case estimate of percentage of pimecrolimus users may not accurately reflect generalizable migration rates, by varying this variable in a sensitivity analysis, the total cost PMPM was found to increase approximately $\$ 0.001$ for each $1 \%$ increase in pimecrolimus users. In addition, by using recent utilization data along with updated pricing to increase the relevance of this analysis to heath plans today, the total cost PMPM was $\$ 0.358$, an increment of $\$ 0.015$ from before formulary placement, demonstrating a small budget impact.

Another potential study limitation pertains to our assumption that flare reduction in a clinical trial is directly reflected in reductions in physician visits in real-world practice. If routine follow-up appointments are made, there will be no cost offset from a reduction in the costs of physician office visits. It is also possible that the number of physician visits may have been 
underestimated if more patients begin seeking medical care for treatment of $\mathrm{AD}$ when an alternative to topical steroid therapy becomes available. In this budget impact model, attempts were made to address this limitation by including patients with their first diagnosis of AD in 2002 and who were prescribed pimecrolimus. In addition, when examining only the pharmacy impact, assuming no reduction in physician visits, PMPM increased minimally by $\$ 0.008$.

Further, an assessment of the patient's disease severity was not possible in this pharmacy and medical claims database analysis, and costs associated with adverse events caused by treatments were not considered. Ninety percent of AD patients suffer from mildto-moderate disease, ${ }^{27}$ which accounts for $90 \%$ of $\mathrm{AD}$ visits to dermatologists. ${ }^{28}$ Before the introduction of pimecrolimus, topical corticosteroids were the mainstay of pharmacological management for AD. However, duration and intensity of corticosteroid therapy is generally restricted for children because of potential treatment side effects. ${ }^{20-31}$ By managing the mildto-moderate $\mathrm{AD}$ patients more effectively using medications with better side-effect profiles, a reduction in physician visits due to better control of $\mathrm{AD}$ and avoidance of potential adverse events may occur. These factors will change the budgetary impact and should be taken into consideration. The conduct of sensitivity analysis on several variables helps to address some of the limitations in the model assumptions.

\section{Conclusion}

Given the estimated percentage of patients seeking care for AD (3.2\%) from this pharmacy and medical claims database analysis, this budget impact model demonstrates that a relatively minimal incremental budget impact of pimecrolimus would be expected. The estimated incremental increase in pharmacy benefit cost in 2003 dollars was $\$ 0.008$ PMPM, but the incremental total combined medical and pharmacy cost was reduced to \$0.002 PMPM after accounting for the projected reduction in physician visit costs. Incremental total costs of $\$ 0.002$ PMPM represented a $0.7 \%$ increase in all AD-related costs. Health plans should perform their own budget forecast modeling using assumptions derived from their own pharmacy and medical claims data for pimecrolimus and the treatment of AD.

\section{ACKNOWLEDGMENT}

We wish to acknowledge Shelby Reed, $\mathrm{RPh}, \mathrm{PhD}$, assistant research professor, Duke University School of Medicine, and Jennifer Stoddard, MSPH, research assistant, Duke Clinical Research Institute, Durham, North Carolina, for their technical and editorial support.

\section{DISCLOSURES}

This study was funded by Novartis Pharmaceuticals Corporation, which manufactures Elidel. Author Jennifer Sung is an employee of Novartis Pharmaceuticals Corporation, and author Jane Chang is an employee of Duke Clinical Research Institute under the Novartis/Duke Outcomes Research Fellowship. This manuscript was presented in part as a poster at the Academy of Managed Care Pharmacy's 16th Annual Meeting \& Showcase, March 2004, San Francisco, California. A second abstract of additional data will be presented, in part, as a poster at the American Academy of Dermatology's 63rd Annual Meeting, February 2005, New Orleans, Louisiana. Chang served as principal author of the study. Study concept and design, analysis and interpretation of data, drafting of the manuscript and its critical revision, and statistical expertise were contributed by both authors.

\section{REFERENCES}

1. National Institute of Arthritis and Musculoskeletal and Skin Diseases Handout on health: atopic dermatitis. Available at: http://www.niams.nih.gov/ hi/topics/dermatitis/index.html\#link_b. Accessed June 15, 2004.

2. Schultz-Larsen F, Holm NV, Henningsen K. A genetic-epidemiologic study in a population-based twin sample. J Am Acad Dermatol. 1986;15:487-94

3. Nevot S, Lleonart R, Casas R. Atopic dermatitis today. Allergol Immunopathol (Madr). 1997;25(4):203-08

4. Diepgen TL. Atopic dermatitis: the role of environmental and social factors, the European experience. J Am Acad Dermatol. 2001;45(suppl 1):S44-S48.

5. Leung DYM. Atopic dermatitis: new insights and opportunities for therapeutic intervention. J Allergy Clin Immunol. 2000;105:860-76.

6. Eichenfield LF, Hanifin JM, Beca LA, et al. Atopic dermatitis and asthma parallels in the evolution of treatment. Pediatrics. 2003;111(3):608-16.

7. Wuthrich B. Clinical aspects, epidemiology, and prognosis of atopic dermatitis. Ann Allergy Asthma Immunol. 1999;83:464-70.

8. Beck LA, Leung DY. Allergen sensitization through the skin induces systemic allergic responses. J Allergy Clin Immunol. 2000;106(suppl 5):S258-S263.

9. Bergmann RL, Edenharter G, Bergmann KE, et al. Atopic dermatitis in early infancy predicts allergic airway disease at 5 years. Clin Exp Allergy. 1998; 28:965-70.

10. Brinkman L, Raaijmakers JA, Bruijnzeel-Koomen CA, Koenderman L, Lammers JW. Bronchial and skin reactivity in asthmatic patients with and without atopic dermatitis. Eur Respir J. 1997;10:1033-40.

11. Ellis CN, Drake LA, Prendergast MM, et al. Cost of atopic dermatitis and eczema in the United States. J Am Acad Dermatol. 2002;46:361-70.

12. Fivenson D, Goldberg RJ, Kaniecki DJ, Cohen JL, Frech F, Finlay AY. The effect of atopic dermatitis on total burden of illness and quality of life on adults and children in a large managed care organization. J Manag Care Pharm. 2002;8(5):333-42

13. Bode HH. Dwarfism following long-term topical corticosteroid therapy. JAMA. 1980;244:813-14.

14. Kristmundsdottir F, David TJ. Growth impairment in children with atopic eczema. J R Soc Med. 1987;80:9-12.

15. Fisher DA. Adverse effects of topical corticosteroid use. West J Med. 1995;162:123-26

16. Ellison JA, Patel L, Ray DW, David TJ, Clayton PE. Morning plasma cortisol levels in infants treated with topical fluorinated glucocorticosteroids. Pediatrics. 1980;65:103-06.

17. Charman C, Morris AD, Williams HC. Topical corticosteroid phobia in patients with atopic dermatitis. Br J Dermatol. 2000;142:931-36.

18. Paller AS, McAlister RO, Doyle JJ, Jackson A. Perceptions of physicians and pediatric patients about atopic dermatitis, its impact, and its treatment. Clin Pediatr. 2002;41:323-32.

19. Ho VC, Gupta A, Kaufmann R, et al. Safety and efficacy of nonsteroid pimecrolimus cream $1 \%$ in the treatment of atopic dermatitis in infants. J Pediatr. 2003;142:155-62.

20. Wahn U, Bos JD, Goodfield M, et al. Efficacy and safety of pimecrolimus cream in the long-term management of atopic dermatitis in children. Pediatrics. July 2002;110(1 pt 1):e2.

21. Meurer M, Fölster-Holst R, Wozel G, et al. Pimecrolimus cream in the long-term management of atopic dermatitis in adults: a six-month study. Dermatology. 205:271-77. 
22. Kapp A, Papp K, Bingham A, et al. Flare Reduction in Eczema with Elidel (infants) multicenter investigator study group. Long-term management of atopic dermatitis in infants with topical pimecrolimus, a nonsteroid antiinflammatory medication. J Allergy Clin Immunol. 2002;110:277-84.

23. Centers for Medicare and Medicaid Services. 2003 Medicare physician fee schedule. Available at: http://www.cms.hhs.gov/providers/pufdownload/ carrpuf.asp. Accessed May 24, 2004.

24. AnalySource Online. Available at: http://www.analysource.com. Accessed August 15, 2003, and November 15, 2004.

25. Foley P, Zuo Y, Plunkett A, Marks R. The frequency of common skin conditions in preschool-age children in Australia: atopic dermatitis. Arch Dermatol. 2001;137:293-300.

26. Buffum WP, Settipane GA. Prognosis of asthma in childhood. Am J Dis Child. 1966;112:214-17.
27. McAlister RO, Tofte SJ, Doyle JJ, Jackson A, Hanifin JM. Patient and physician perspectives vary on atopic dermatitis. Cutis. 2002;69:461-66.

28. Scott-Levin PDDA audit data. April 2000.

29. Hoare C, Li Wan Po A, Williams H. Systematic review of treatments of atopic eczema. Health Technol Assess. 2000;4:1-91.

30. Van Der Meer JB, Glazenburg EJ, Mulder PG, Eggink HF, Coenraads PJ. Management of moderate to severe atopic dermatitis in adults with topical fluticasone propionate. The Netherlands Adult Atopic Dermatitis Study Group. Br J Dermatol. 1999;140:1114-21.

31. Hanifin J, Gupta AK, Rajagopalan R. Intermittent dosing of fluticasone propionate cream for reducing the risk of relapse in atopic dermatitis patients. Br J Dermatol. 2002;147:528-37. 